Christke S, Gibson AG, Grigoriou K, Mouritz AP.

Multi-layer polymer metal laminates for the fire protection of lightweight structures.

Materials and Design 2016, 97, 349-356

\section{Copyright:}

(C) 2016. This manuscript version is made available under the CC-BY-NC-ND 4.0 license

DOI link to article:

http://dx.doi.org/10.1016/j.matdes.2016.02.105

Date deposited:

$16 / 03 / 2016$

Embargo release date:

24 February 2017

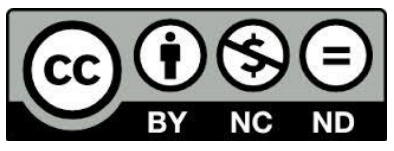

This work is licensed under a

Creative Commons Attribution-NonCommercial-NoDerivatives 4.0 International licence 


\title{
MULTI-LAYER POLYMER METAL LAMINATES FOR THE FIRE PROTECTION OF LIGHTWEIGHT STRUCTURES
}

\author{
S. Christke ${ }^{\mathrm{a}, *}$ and A.G. Gibson ${ }^{\mathrm{a}}$ \\ ${ }^{a}$ Centre for Composite Materials Engineering, Newcastle University, Newcastle-upon-Tyne, Newcastle, NE1 \\ 7RU, United Kingdom \\ K. Grigoriou ${ }^{b}$, A.P. Mouritz ${ }^{b}$ \\ ${ }^{b}$ Sir Lawrence Wackett Aerospace Research Centre, School of Aerospace, Mechanical \& Manufacturing \\ Engineering, RMIT University, GPO Box 2476, Melbourne, VIC 3001, Australia \\ * Corresponding author.
}

\begin{abstract}
A multi-layer polymer metal laminate (PML) system is described, which can be used to thermally insulate lightweight structural materials, such as aluminium or carbon fibre reinforced plastic (CFRP) composite, when exposed to fire. The system comprises many thin adhesively-bonded metal foils, bonded directly to the structural substrate. When exposed to fire the PML adhesive thermally decomposes with the generation of volatiles, causing the foils to delaminate and inflate, thus greatly reducing its thermal conductivity. The expanded PML slows heat transfer from the fire into the structural substrate, resulting in lower temperatures and increased structural survivability. The fire protection effects of two different thicknesses of PML are demonstrated here for both aluminium and CFRP substrates. Fire exposure tests demonstrate that the substrate temperatures are reduced and the time to failure under load is substantially improved. The protection offered is equivalent or superior to conventional fire protection materials such as ceramic fibre mat or intumescent coatings. The advantage of the PML is that, in non-fire conditions, it contributes to the appearance and load-bearing capability of the structure without being prone to damage or water absorption.
\end{abstract}

KEYWORDS: fire protection, multi-layer laminate, composites, CFRP, aluminium, structural survivability

\section{INTRODUCTION}

An important consideration in the use of metal alloys and polymer composites in high fire risk applications (e.g. aircraft, ships, offshore platforms) is their structural survivability [1,2]. Fire structural survivability can be defined as the capacity of the material used in a load-bearing structure to retain stiffness, strength and creep resistance so that it resists excessive 
deformation or failure for a specified period of time when exposed to fire. This is a major issue, especially for light-weight structural materials with low softening temperatures such as aluminium alloys and polymer composites, especially those used in aerospace. For example, the stiffness and yield strength of most aluminium alloys begin to decrease and the creep rate increases rapidly in the range $150-200{ }^{\circ} \mathrm{C}$, resulting in relatively poor load-bearing performance [3-11]. CFRP loses much of its compressive and flexural load-bearing capacity above the glass transition temperature which, for aerospace applications is typically in the range $180-210{ }^{\circ} \mathrm{C}$. At $300-350{ }^{\circ} \mathrm{C}$ most polymer-based composite materials begin to decompose with the evolution of flammable volatiles. These release heat, adding to the fuel load of the fire and leading to flashover $[12,13]$.

A number of different classes of passive fire protection (PFP) have been developed to insulate the load-bearing substrates from fire. They all function by forming a low density, air or gascontaining structure which achieves its thermal resistance by immobilising the gas within it. The thermal conductivity of such structures is generally of the order of $0.01-0.05 \mathrm{~W} / \mathrm{m} / \mathrm{K}$, regardless of the type of material. To obtain lower conductivities it is necessary to generate nano-scale porosity below the mean free path of the gas molecules [14-16] which most current PFPs do not employ.

Current PFPs may be broadly divided into the following categories:

(i) Mineral-based refractory fibre systems (typically based on glass, alumina, kaolin or rockwool) that achieve low thermal conductivity by immobilising the air within them [17].

(ii) Mineral-based refractory non-fibrous systems, such as vermiculite and expandable graphite, which achieve low conductivity in fire by intumescence $[18,19]$.

(iii) Syntactic coatings (e.g. glass or ceramic micro-balloons in a polymer matrix) which have low conductivity [20,21].

(iv) Intumescent organic coating systems, based on an acid source, such as ammonium polyphosphate, a carbon source such as a long chain alcohol and a 'spumifiant' or blowing agent such as melamine. These react in fire, increasing several times in volume to create a highly porous (expanded) refractory carbonaceous char with low thermal conductivity [22-24]. 
Other types of coating, which have the potential to offer fire protection, include geopolymers [26-28], polymers modified with nanofillers and carbon nanofiller-based papers [29,30].

Systems (i) and (ii) above are the most widely-used for fire protection in the marine, offshore and other sectors. Thin film intumescent systems are also commonly used, although they have limited durability when exposed to severe environmental conditions (e.g. abrasion, erosion, moisture). A key problem with all of the coating systems described above is that, in terms of structural behaviour, they are parasitic. In other words, they contribute to the weight of a structure without adding to its stiffness or strength, only fulfilling a useful role in the rare event of a fire. Such coatings may also affect the appearance of the surface to which they are attached, and can be subject to water absorption and retention which promotes corrosion of the substrate. In aerospace, most of these coatings are non-viable for external use on fuselages, either because they affect aerodynamic behaviour or are sensitive to erosion.

This paper reports on a non-parasitic protection system based on multi-layered polymer metal laminates (PML) bonded using thin layers of adhesive. In normal operating conditions the PML contributes to mechanical performance since it is integral to the structure and has high specific strength and specific stiffness relative to the coating systems described above. In fire, the PML delaminates internally and swells in a similar manner to expandable graphite or vermiculite, to produce a stable delaminated 'filo pastry'-like structure capable of thermally insulating the underlying substrate.

It is relevant to acknowledge that metal/composite laminates such as GLARE and ARALL $[31,32]$ are well-known in aerospace, where they are acknowledged to confer improved burnthrough characteristics on aircraft fuselages, compared to aluminium skins alone. However, these materials are primarily designed to improve fatigue and damage tolerance. In contrast, the PMLs reported here contain no reinforcement, being designed principally to contain the maximum number of delaminatable interfaces, to promote their resistance role in fire. Their mechanical properties in the pristine state reflect those of the aluminium of the foils.

This paper presents an experimental investigation into the fire protection mechanism of PML, and its capacity to thermally insulate and improve the fire structural survivability of substrates which soften at relatively low temperature (aluminium and carbon fibre composite). The paper 
compares the thermal protection provided by PML against some conventional fire protective coatings; namely mineral-based refractory fibre and intumescent coatings.

\section{MATERIALS AND EXPERIMENTAL}

\subsection{Materials}

Fire structural tests were performed on $6.35 \mathrm{~mm}$ thick aluminium and CFRP substrates with and without PML thermal protection. The metal substrate was aircraft-grade aluminium alloy rolled plate (AA2024-T351 supplied by Alcoa), cut into $600 \mathrm{~mm}$ long and $50 \mathrm{~mm}$ wide test specimens.

The CFRP substrate was fabricated from unidirectional carbon fibre-epoxy prepreg tape (AS4/3501-6 supplied by Hexcel Composites). This grade of CFRP was chosen as an example of a typical aerospace composite. The composite laminate was designed with a thickness similar to that of the AA2024 substrate. Thus, 24 CFRP prepreg plies were stacked in a quasiisotropic pattern $\left[0^{\circ} / 45^{\circ} / 90^{\circ} /-45^{\circ}\right]_{\mathrm{s}}$ to construct a symmetric and balanced composite, debulked, vacuum bagged, then consolidated and cured in an autoclave according to the manufacturer's instructions. The final thickness of the cured CFRP panels was $6.7 \mathrm{~mm}$ with a fibre volume fraction of 0.62 and the glass transition temperature was $210^{\circ} \mathrm{C}$, as determined by DSC at $20 \mathrm{~K} / \mathrm{min}$. The CFRP panels were water jet-cut into test specimens of the same dimensions as the aluminium ones. Isothermal tensile tests were also carried out on $25 \mathrm{~mm}$ wide, end-tabbed specimens cut from the same material.

The metal laminates, shown schematically in Figure 1, comprised $30 \mu \mathrm{m}$ thick $99 \%$ purity aluminium foils separated by $\sim 10 \mu \mathrm{m}$ layers of epoxy resin of type RS-L135 supplied by PRF Composite Materials. They were prepared by a prototype manual coating and rolling process, which resulted in a void content of approximately $5 \%$ due to air entrapment. This was followed by a post-curing step according to the manufacturer's specifications. 10-foil thick and 20-foil thick laminates were prepared, giving protection layers of $\sim 0.4 \mathrm{~mm}$ and $\sim 0.8 \mathrm{~mm}$, respectively. In preparation for testing, strips of these laminates were bonded onto one side of the aluminium alloy and CFRP specimens with the same resin. 


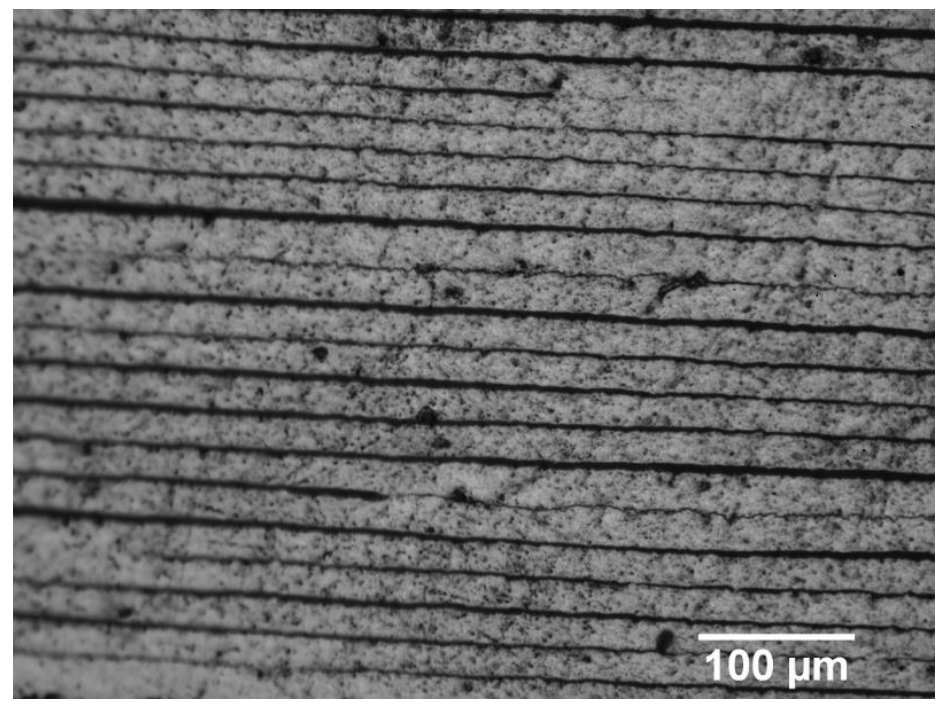

Figure 1. Cross-sectional optical micrographic image of the 20-ply multi-layered metal laminate with the alternating sequence of $30 \mu \mathrm{m}$-thick aluminium foils (light grey colour) separated by polymer interlayers (black colour) which are less than $10 \mu \mathrm{m}$ thick.

To provide a comparison with the thermal behaviour of the PML, some additional samples were prepared with two conventional PFPs: a commercial intumescent and a system based on a refractory fibre wool. The intumescent was $0.6 \mathrm{~mm}$ thick coating of FireFree88, which is a water-based, organic coating capable of withstanding fire temperatures up to $\sim 1100{ }^{\circ} \mathrm{C}$ for up to $2 \mathrm{~h}$ according to the product manufacturer (Firefree Coatings Inc, USA). The mineral-based refractory fibre system was a $0.8 \mathrm{~mm}$ thick mat known as Superwool 607 HT (Thermal Ceramics, USA) which provides thermal protection up to $\sim 1300{ }^{\circ} \mathrm{C}$. The fibre mat coating was bonded to the substrates using a high temperature adhesive (FCL007 supplied by Fire Protect, Chester UK Ltd), which is thermally stable up to $\sim 1000^{\circ} \mathrm{C}$.

The fire-exposed surfaces of both the protected and unprotected test specimens were spraypainted with heat-resistant mat black paint, to maximise heat transfer into the sample and to ensure that all sample types had the same surface absorptivity and emissivity. Ceramic wool fibre blanket was wrapped as thermal insulation around all edges leaving only a $100 \mathrm{~mm}$ long window open at the front for fire exposure.

Tensile tests were carried at temperatures between $20^{\circ} \mathrm{C}$ and $400^{\circ} \mathrm{C}$. The CFRP specimens were $150 \mathrm{~mm}$ long, $25 \mathrm{~mm}$ wide rectangular strips, with a $60 \mathrm{~mm}$ wide gauge length. The aluminium samples were $20 \mathrm{~mm}$ wide dog-bones. The specimens were tested until failure at a rate of $2 \mathrm{~mm} / \mathrm{min}$. For the high temperature measurements the heated gauge length method 
[33] was used during which the specimen gauge length is heated up locally inside a temperature-controlled aluminium sheath.

\subsection{Heat flux exposure under load}

All the specimens were subjected to heat flux exposure under load, as shown in Figure 2. The test involved subjecting the specimen to a constant tensile or compressive load, along with a constant one-sided radiant heat flux. This test simulates the condition of a load-bearing material being exposed to the heat radiated by fire. A full description of the fire structural test procedure is provided by Feih et al. [34], but is briefly outlined here. Each specimen was axially pre-loaded to a constant tensile or compressive stress using a $250 \mathrm{kN}$ load capacity MTS servo-hydraulic machine. The applied tensile stress was between 5\% and $90 \%$ of the room temperature strength values, which were $347 \mathrm{MPa}$ (proof stress) for the aluminium and $588 \mathrm{MPa}$ (failure stress) for the CFRP. Similarly, for the tests involving compressive load, the applied stress was between $5 \%$ and $90 \%$ of the room temperature global buckling stress, which was $39 \mathrm{MPa}$ for the aluminium and $24 \mathrm{MPa}$ for the CFRP.
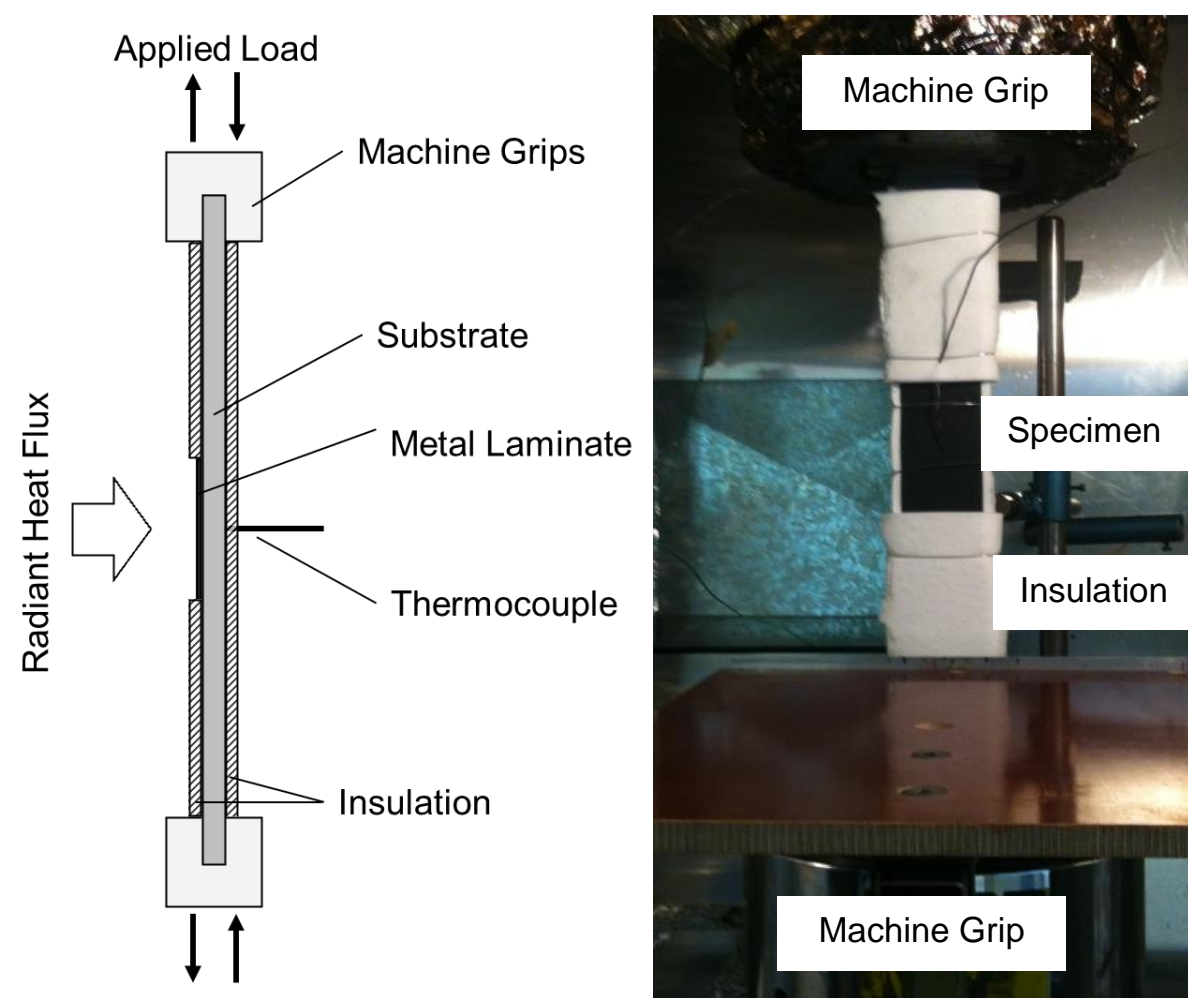

Figure 2. Experimental setup for fire-structural testing. 
Once under the constant tensile or compressive stress, the specimen was suddenly exposed to a constant thermal flux of $50 \mathrm{~kW} / \mathrm{m}^{2}$ from a $150 \mathrm{~mm}$ diameter radiant electrical heater, which was capable of being pre-heated, then rapidly moved to a location $25 \mathrm{~mm}$ from the front face. The conical heating element was similar to those used in a cone calorimeter. As shown in Figure 2, a $100 \mathrm{~mm}$ long 'window' at the centre of each specimen was exposed directly to the thermal flux, while the remainder of the sample was masked off to give a well-defined heated gauge length. The sides of the samples were also insulated and the upper and lower parts were provided with further mineral insulation to minimise excessive heating of the loading machine. K-type thermocouples were attached to the front and back surfaces of each specimen to record the temperatures over the duration of the fire exposure test. The axial deformation of the specimen during the test was measured directly from the crosshead movement of the machine. The lateral deflection of the specimen was measured using a linear variable differential transducer (LVDT) placed against the rear (colder) surface. As mentioned, each specimen was subjected to constant stress and one-sided thermal flux, up to the point of rupture in tension or buckling in compression. In all cases failure was observed to be a well-defined fairly rapid event, marked by an accelerating cross-head movement for no change in load.

\section{RESULTS AND DISCUSSION}

\subsection{Substrate Mechanical Properties}

Figure 3 shows the effect of temperature on the Young's modulus and tensile strength of the aluminium and CFRP. Both materials can be seen to begin to lose properties at relatively low temperatures. The tensile resistance is defined, for aluminium by the yield stress and for the CFRP by the ultimate rupture stress. The aluminium begins to soften significantly at about 150 ${ }^{\circ} \mathrm{C}$ and has lost $50 \%$ of its ambient temperature tensile properties by $\sim 350{ }^{\circ} \mathrm{C}$. Similar results for other aluminium alloys have been reported elsewhere [7,11]. CFRP retains a higher proportion of tensile strength and modulus at higher temperature, reflecting the thermal insensitivity of the $0^{\circ}$ fibres. The observed spread in the results of the CFRP tensile experiments can be explained by irregularities in the alignment of individual CFRP plies which are introduced during the manufacturing process resulting in minimal deviations from the planned fibre orientation leading to slight variations in the overall material strength. No CFRP compressive properties are reported here, but it is well-known that the compressive strength of CFRP, being resin-dominated, deteriorates significantly above $100^{\circ} \mathrm{C}$ and falls to a low value as the glass transition temperature of the epoxy is approached. 


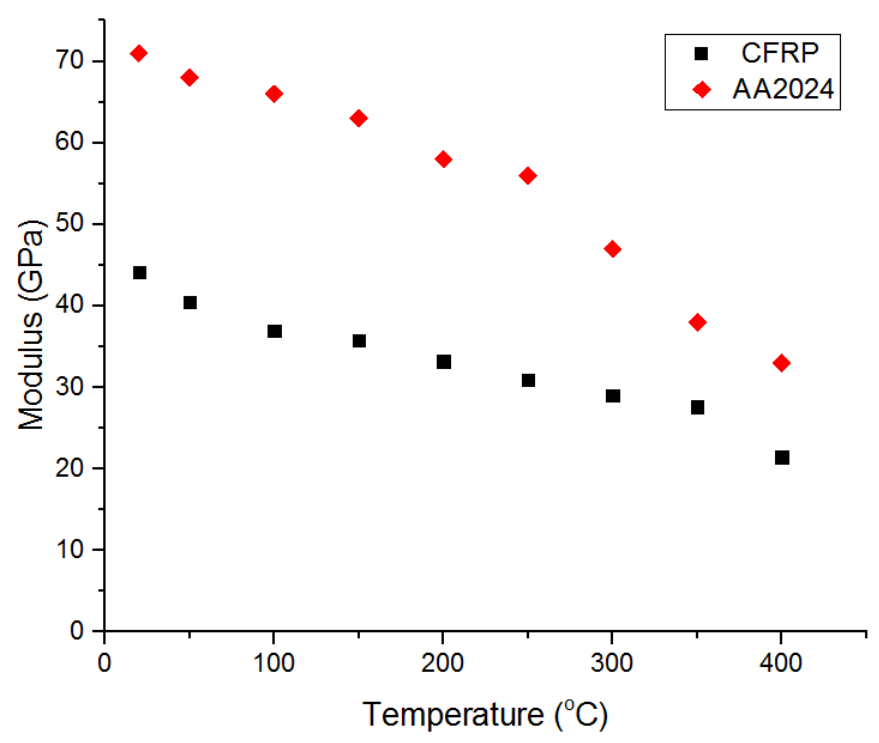

(a)

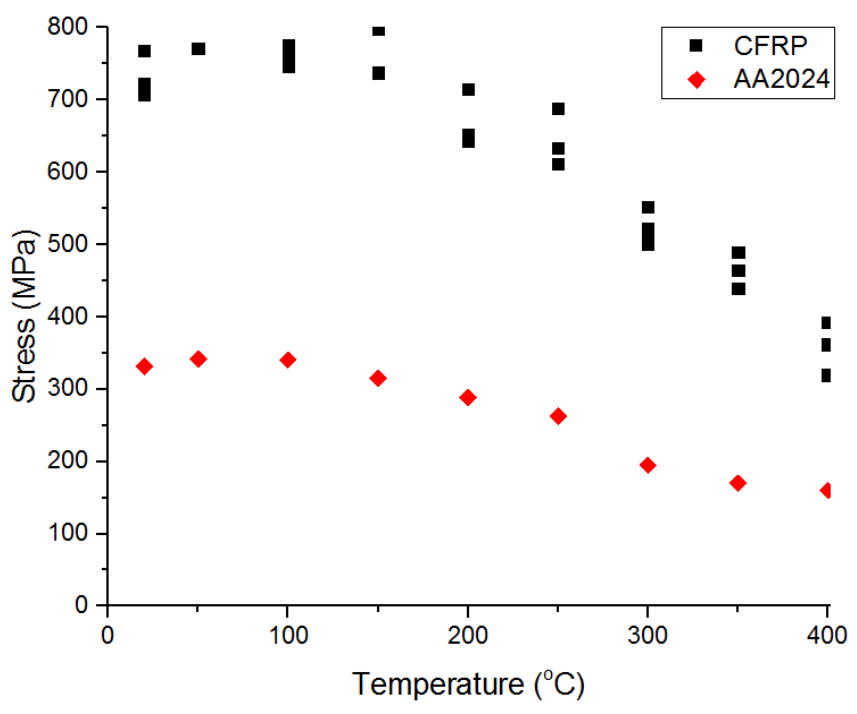

(b)

Figure 3. Effect of temperature on the (a) Young's modulus and (b) tensile strength of the aluminium and composite materials.

\subsection{Thermal Insulation Effect of the PML}

Figure 4 shows the back-face temperatures measured for the aluminium and CFRP specimens with and without PML when exposed to the heat flux. The unprotected aluminium heated up rapidly within the initial $\sim 15$ min of direct exposure to the thermal flux and then reached a near thermal equilibrium condition when the temperature was relatively stable at $\sim 330{ }^{\circ} \mathrm{C}$. The 
PMLs were highly effective at insulating the aluminium substrate, which heated at a slower rate and reached a lower plateau temperature of $\sim 280{ }^{\circ} \mathrm{C}, 50{ }^{\circ} \mathrm{C}$ cooler than without the thermal barrier. Surprisingly, the insulating effect was very similar with the two PML thicknesses that were studied. The temperature plateau in the aluminium case was mainly due to its high thermal conductivity, which resulted in significant heat losses by axial conduction into the parts of the specimen around the exposed region, and ultimately into the machine grips. The thermal plateau corresponds to the equilibrium situation where the heat entering the sample through the front face is balanced by that leaving it by axial conduction plus rear face convection.

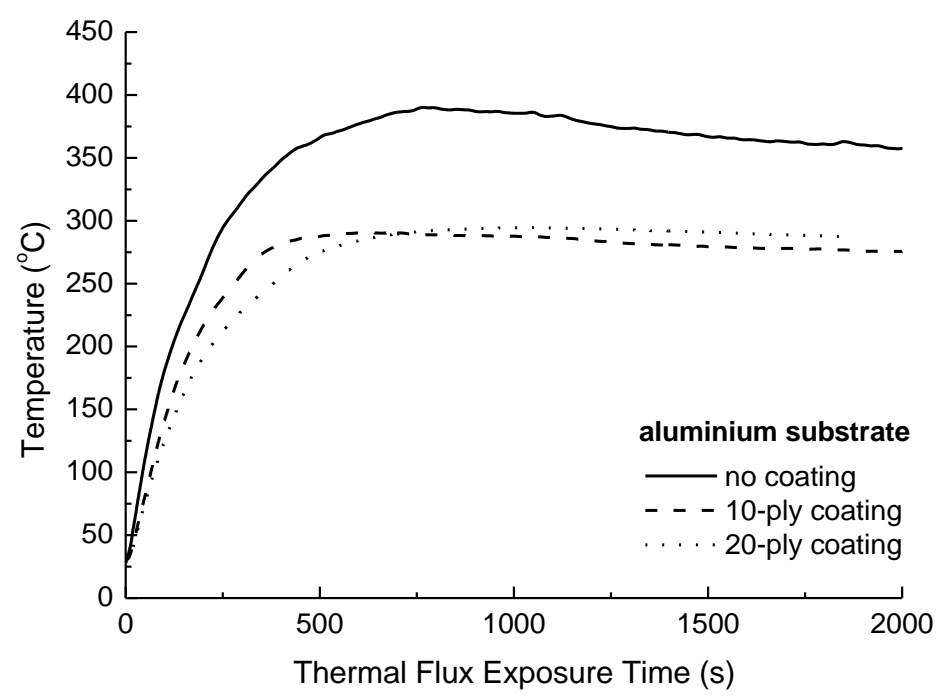

(a)

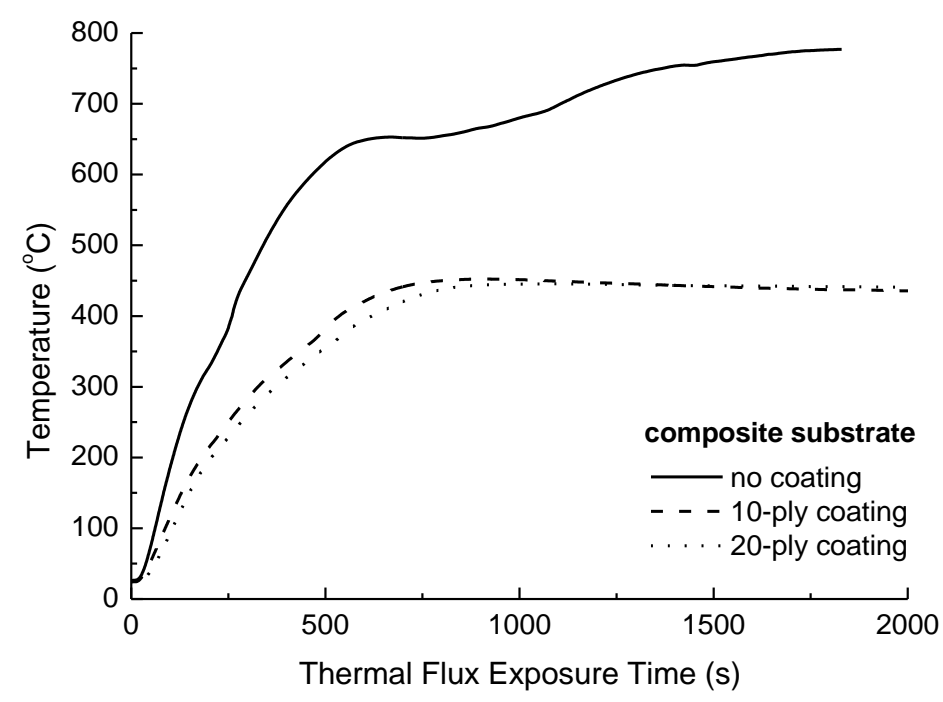

(b) 
Figure 4. Effect of thermal flux exposure time on the rear-face temperatures of the (a) aluminium and (b) composite substrates with and without the multi-layered metal laminate coating.

The insulating effect of the PML was even more apparent for the CFRP. The rear temperature of the unprotected composite increased to $\sim 800{ }^{\circ} \mathrm{C}$, with the surface exhibiting 'flashover' a short way into the test, due to the ignition of flammable organic volatiles from decomposition of the epoxy matrix. The higher temperatures, compared to aluminium, were due mainly to much lower axial conduction in the CFRP case, bearing in mind that the in-plane thermal conductivity is about 50 times lower than for aluminium. The PML significantly reduced the heating rate of the CFRP and maintained a much lower temperature $\left(\sim 420^{\circ} \mathrm{C}\right)$, and as a result the protected composite did not ignite and burn. As with the aluminium, the plateau temperature reached for the CFRP was rather similar for the two PML thicknesses studied.

It should be noted that the through-thickness conductivity of the CFRP is about $1 / 4$ of the axial value and therefore about 200 times lower than that of the aluminium. This means that the CFRP would have experienced a large temperature gradient from the front to the rear face, whereas the through-thickness gradient in the case of the aluminium would have been negligible.

\subsection{Insulation Mechanism of the PML}

The lower temperatures of the aluminium and composite substrates when insulated with the PML were due to the expansion mechanism illustrated in Figure 5. The insulating effect is created via the decomposition of the epoxy resin which results in gas evolution, causing delamination of the layers and separation into a 'filo'-like structure with a multiplicity of interfaces, each with its own significant thermal resistance. The degradation temperature range of the resin is between about $300{ }^{\circ} \mathrm{C}$ and $400{ }^{\circ} \mathrm{C}$, the maximum degradation rate occurring at about $350{ }^{\circ} \mathrm{C}$. TGA measurements show that typically $80-90 \%$ of the original resin mass is converted to volatiles [12]. 

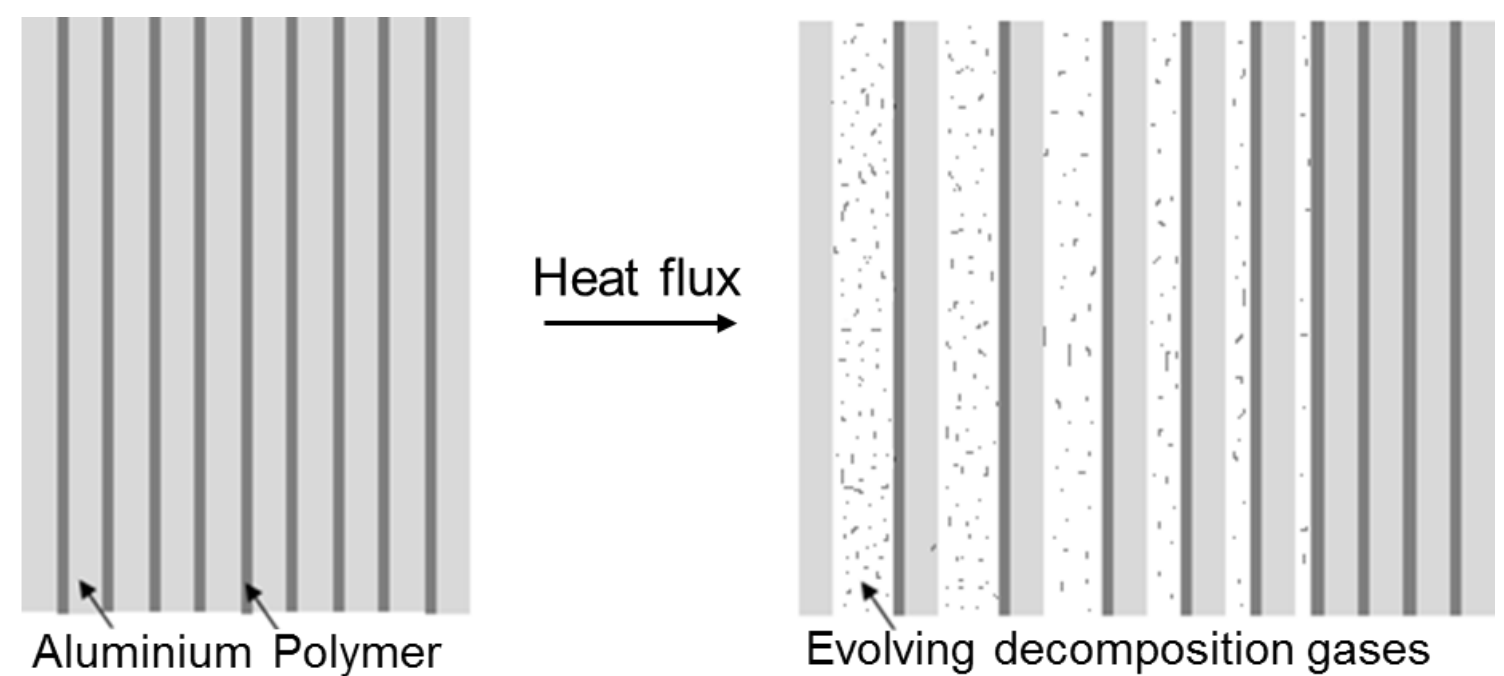

Figure 5. Schematic of the expansion process of the multi-layered metal laminate when exposed to one-sided heating.

Figure 6 shows the cross-section of an expanded PML following heat exposure. It contains delamination between the foil layers which greatly reduce the thermal conductivity. The multilayered PML thermal barriers described here form an insulation system suitable for temperatures up to about the melting point of aluminium $\left(660{ }^{\circ} \mathrm{C}\right)$, at which point the layers begin to melt. Further work is currently under way using similar foil systems to the one reported here, with the aluminium front foil replaced by one of a higher melting point metal.

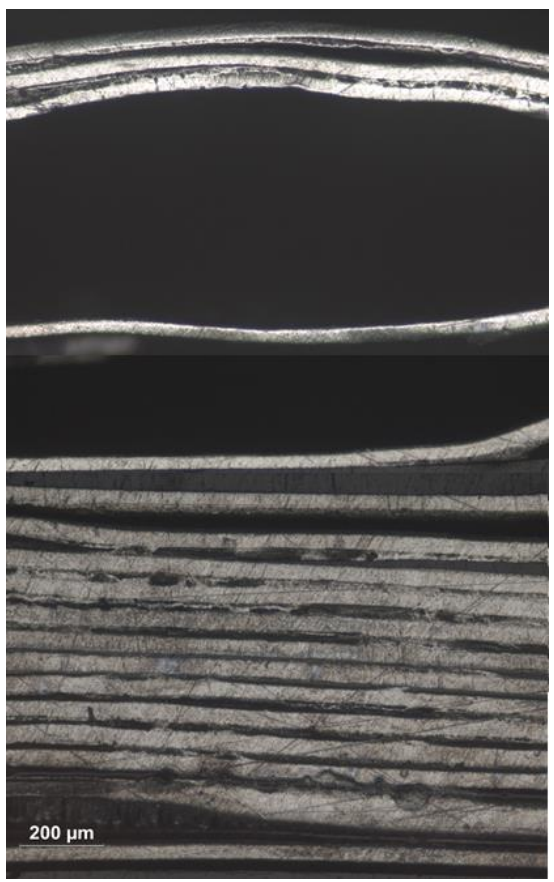

heated surface

substrate 
Figure 6. Cross-section view of the 20-ply multi-layered metal laminate on the aluminium substrate following exposure to the thermal flux. The micrograph shows residual gas pockets which result from the polymer decomposition during exposure to high temperatures.

The expansion process was studied further by performing annealing tests at different temperatures between $350^{\circ} \mathrm{C}$ (close to the decomposition temperature of epoxy) and $500{ }^{\circ} \mathrm{C}$ on the coating. Figure 7 shows the effects of temperature and heating time on the expansion factor of the 10-ply insulation system. The expansion factor defines the increase in coating thickness at elevated temperature compared to the original thickness. Above $\sim 360{ }^{\circ} \mathrm{C}$ the expansion factor increases rapidly with temperature and time, due to the gas from the resin decomposition. At the highest temperature studied $\left(500^{\circ} \mathrm{C}\right)$ the coating swelled rapidly (within a few minutes) and reached a steady-state expansion factor of about 9. This degree of swelling of the PML is similar to that of many commercial intumescents [12,22-24].

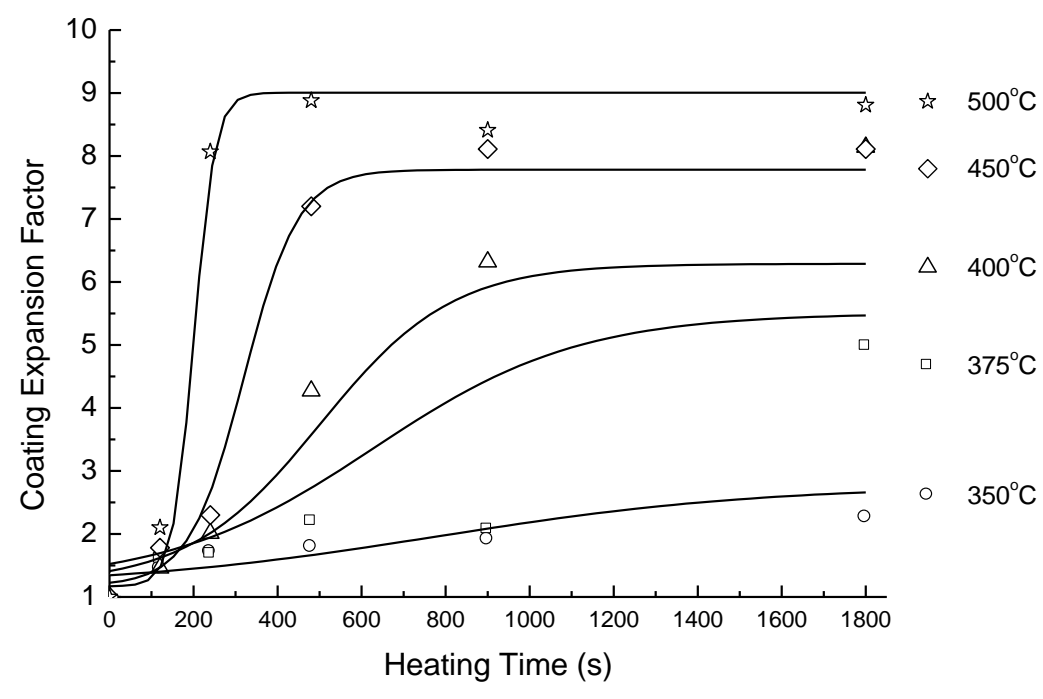

Figure 7. Effects of temperature and heating time on the thermal expansion factor of the 10-ply multi-layered metal laminate coating.

\subsection{Improved Fire Structural Protection with the PML}

Fire structural tests were performed on the aluminium and CFRP substrates with and without thermal protection provided using the PML. Figure 8 shows the typical effect of increasing exposure time on the axial extension of the bare and protected materials under constant tensile stress. Deformation of the aluminium is caused by thermal expansion, the reduction in the Young's modulus (as shown in Figure 3) and ultimately creep-induced plastic flow [4,7,11]. The extension rate increases steadily with exposure time until the aluminium begins to neck, at which time the extension rate increases rapidly followed soon after by rupture. The extension 
rate of the aluminium was slowed substantially by the 10-ply PML and more so by the 20-ply PML. Similar behaviour was observed for the aluminium under compressive loading; the deformation rate was slowed by the 10-foil PML and more so by the 20-foil PML.

The PMLs were also effective at delaying the tensile failure of the composite (Figure $8 \mathrm{~b}$ ). The bare composite deformed rapidly due to softening and decomposition of the epoxy matrix and heat-induced weakening of the carbon fibres. Protecting the composite with the PML did not slow the extension rate during the initial heating phase (up to $\sim 500 \mathrm{~s}$ ). Extension of the composite during this phase is caused solely by thermal softening of the epoxy matrix, which occurs around the glass transition temperature $\left(\mathrm{T}_{\mathrm{g}}=210^{\circ} \mathrm{C}\right)$. During the initial phase the surface temperature of the uncoated and coated composites is below the temperature needed to activate expansion of the PML $\left(\sim 360^{\circ} \mathrm{C}\right)$, and therefore it does not provide significant thermal protection to the CFRP substrate. However, at longer thermal flux exposure times (above $\sim 500$ s) the temperature is above the activation temperature of the PML, causing it to expand and insulate the substrate. This considerably slows the deformation rate of the composite, with the thicker PML being more effective. Protecting the composite can also be seen to slow its deformation rate under compression loading.

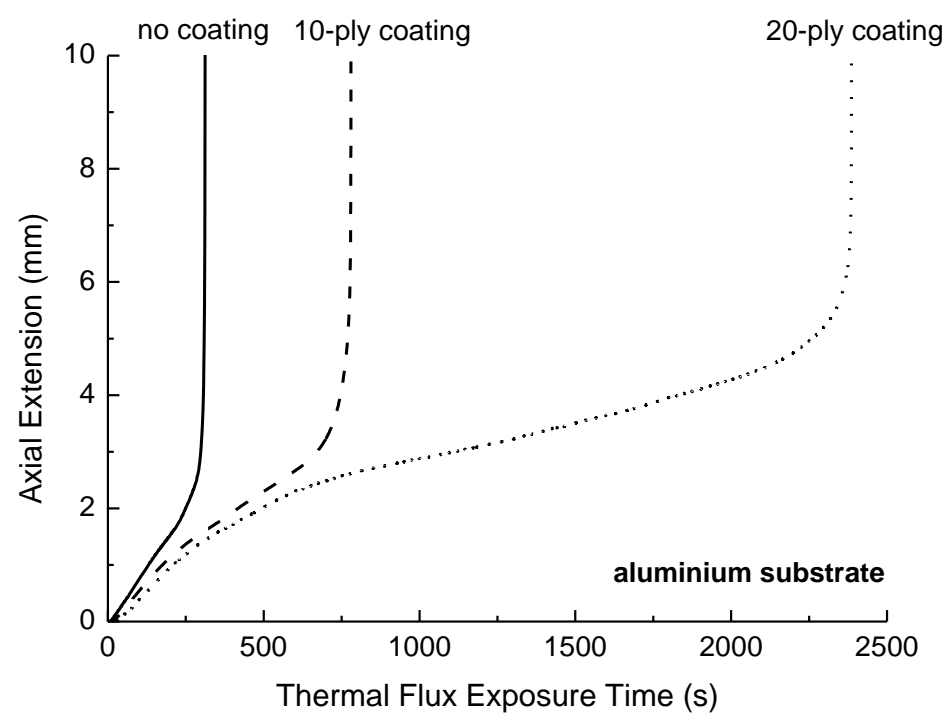

(a) 


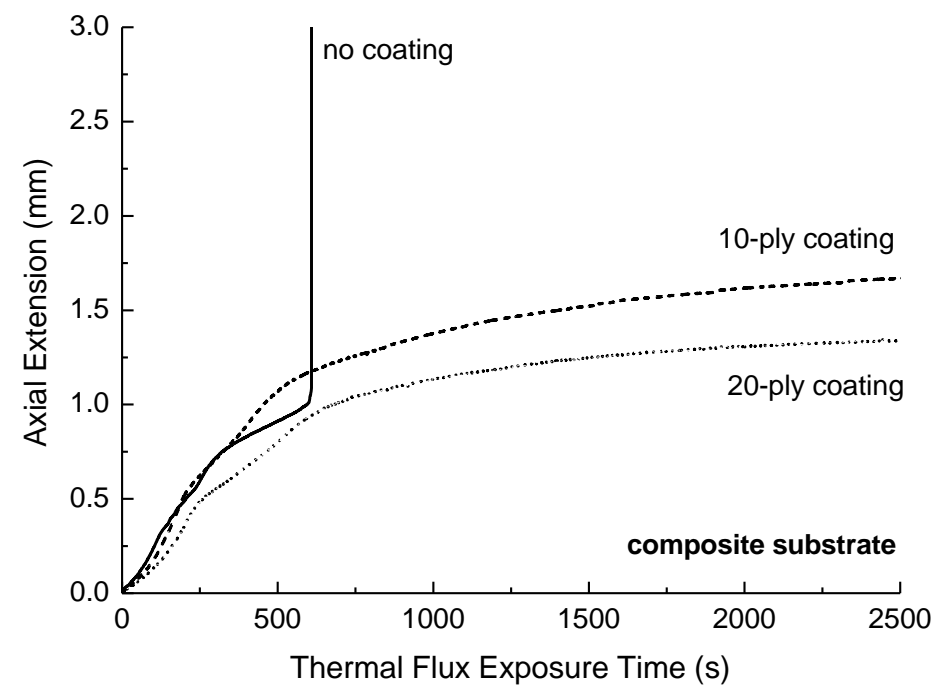

(b)

Figure 8. Effect of thermal flux exposure time on the axial extension of the (a) aluminium and (b) composite substrates with and without the multi-layered metal laminate coating. The aluminium and composites samples were tensile loaded at 50\% and $40 \%$ of their room temperature strength, respectively.

Figures 9 and 10 show the capacity of the multi-layered laminate system to improve the fire structural survival time of the aluminium and CFRP substrates. The figures show plots of the percentage applied tensile and compressive stress on the failure time of the substrates. The applied stress values are a percentage of the failure stress at room temperature. The failure time is the thermal flux exposure time required to cause rupture of the substrate under tensile loading or buckling failure under compressive loading. As expected, the failure times are shorter in compression compared to tension loading, and this is due to the long, slender geometry of the test specimens which aids buckling failure. The results clearly show that the PML increased the failure time of the substrates under both tensile and compressive loads, and this is due to the insulation effect that occurs when the metal foils delaminate and swell due to decomposition of the resin layers. Also, the fire structural survivability increased with the coating thickness due to the prolonged higher insulation. 


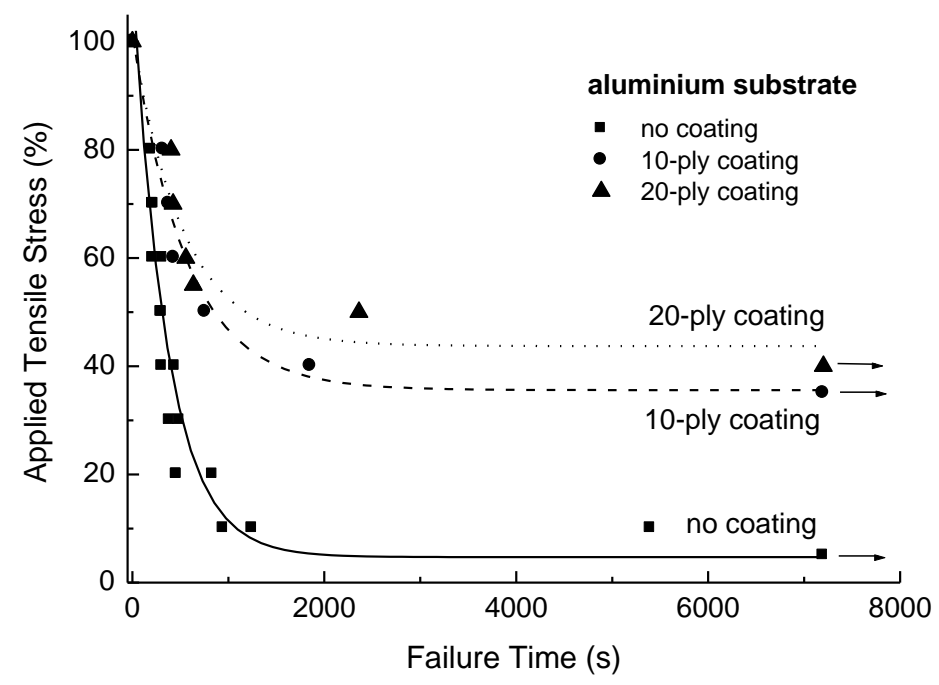

(a)

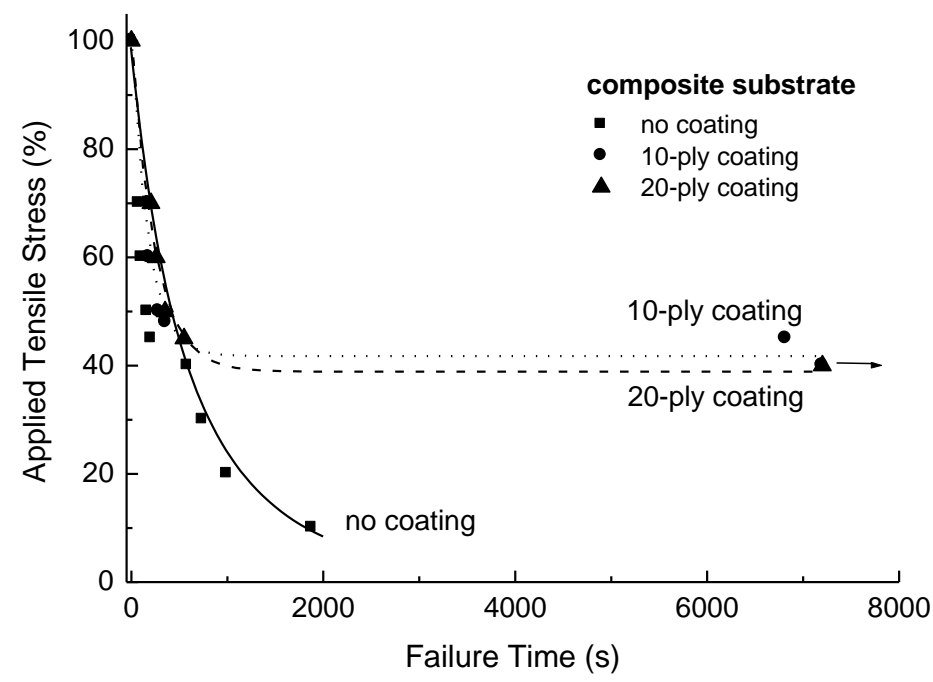

(b)

Figure 9. Plots of applied percentage tensile stress vs failure time curves for the (a) aluminium and (b) composite substrates with and without the multi-layered metal laminate coating. The arrows indicate that failure did not occur after $2 \mathrm{~h}$. 


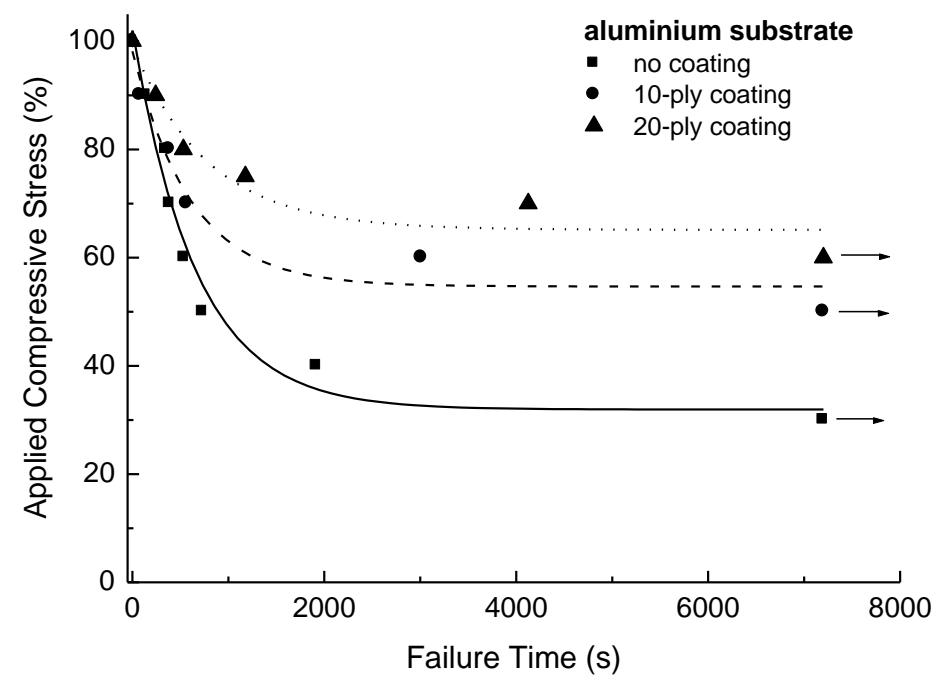

(a)

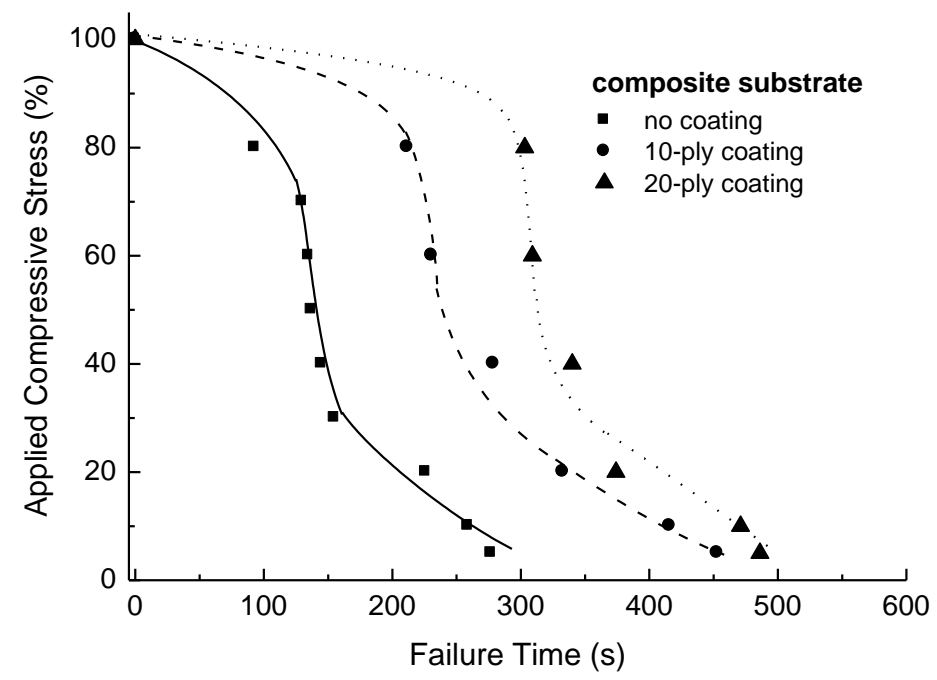

(b)

Figure 10. Plots of applied percentage compressive stress vs failure time curves for the (a) aluminium and (b) composite substrates with and without the multi-layered metal laminate coating. The arrows indicate that failure did not occur after $2 \mathrm{~h}$.

The improvement to the fire protection and structural survivability gained by the PML is similar to conventional ceramic fibre mat and organic intumescent coating systems often used for surface insulation. Figure 11 compares the rear-face temperatures measured for the aluminium substrate protected with the 20-ply multi-layered laminate ( $0.8 \mathrm{~mm}$ thick), ceramic fibre mat coating $(\sim 0.8 \mathrm{~mm})$ and intumescent coating $(\sim 0.6 \mathrm{~mm})$. The insulating effect of the PML is slightly superior to the intumescent coating (although it is also slightly thicker) and less effective than the ceramic fibre mat at short heating times (under $\sim 1 \mathrm{~h}$ ). The steadystate temperature of the substrate was very similar for the three insulation systems, revealing that the PML is as effective as conventional PFPs. The porosity dimensions in the present case 
are of micron size, and thus significantly larger than the mean free path of the trapped gas, so the insulation values of the expanded laminates are comparable with those of conventional insulating materials, rather than nano-insulators. This possibility might be considered for future multi-layer materials but would, of course, require much finer dimensions. Figure 12 compares the fire structural performance of the different coatings for the aluminium substrate under tensile loading. Again, it is found that the PML improves the fire performance by similar amounts as the ceramic fibre mat and intumescent coatings, but having the added benefit of also being load-bearing. Tensile tests on samples with a 20-ply PML coating, corresponding to $6 \%$ of the metal being added to the section, demonstrated that the load-extension curve slope and failure load were both increased by $6 \%$, indicating that the foils contributed proportionately to the load-bearing capacity. This, of course, is in contrast to other fire protection systems, which do not have a significant structural effect.

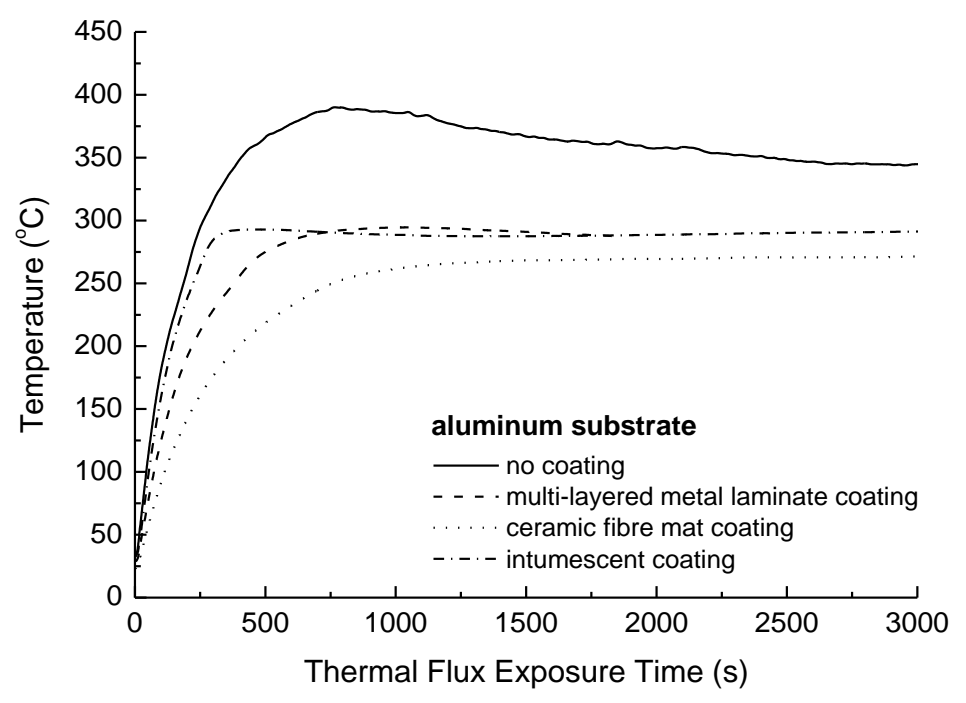

Figure 11. Comparison of the back-face temperatures measured for the aluminium substrate protected with the multi-layered metal laminate (20-ply), ceramic fibre mat or intumescent coating systems. 


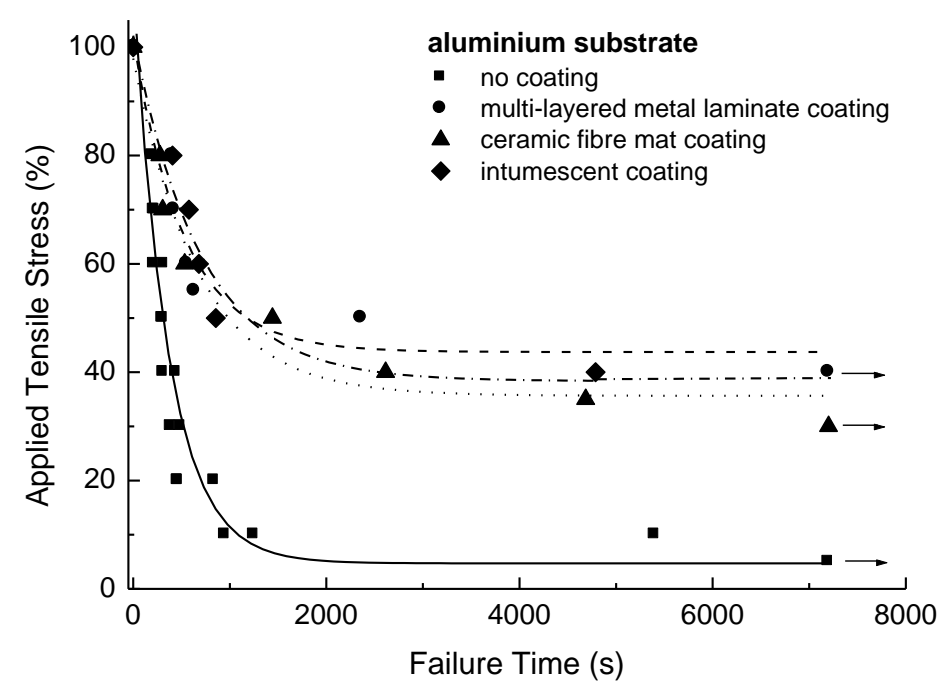

Figure 12. Comparison of the tensile failure times measured for the aluminium substrate protected with the multi-layered metal laminate (20-ply), ceramic fibre mat or intumescent coating systems. The arrows indicate that failure did not occur after 2 hours.

\subsection{Thermal response modelling}

A two-part, one-dimensional finite difference method has been developed to describe the temperature increase within PML-covered specimens when exposed to one-sided heat.

The first section of the model analyses the heat transfer through the PML surface layer. Basic heat conduction theory in combination with resin decomposition reaction according to the Arrhenius equation is applied. Most important is the consideration of the PML expansion which is the main cause for the protection effect. This is realised within the model via a PML expansion parameter that is dependent on the decomposition state of the material and which causes an increase of the spacing between individual grid points with on-going heat exposure time. The model replicates a simplified PML architecture. It is assumed that one polymer interlayer and one aluminium foil form one element which forms the basis for the spatial discretisation in the through-thickness direction of the specimen. Overall temperaturedependent thermal properties (density $\rho$, specific heat capacity $c_{p}$, thermal conductivity $k$ ) of these elements are calculated according to the rule-of-mixtures. mixtures. Some property data of PML, CFRP and aluminium at room temperature, used in the thermal response model, is given in Table 1.

The second part of the model describes the heat transfer across the substrate material of the specimen. For non-reactive metal materials, such as the AA2024, this only includes basic heat conduction equations as the material does not undergo any chemical transformation. Important 
input factors are the respective thermal material properties of $\rho, c_{p}$, and $k$. In case of a reactive substrate, e.g. CFRP composite laminate, heat transfer analysis is performed via routines established within the COM_FIRE program [35]. This in turn is based on the Henderson equation [36] which includes the effects of endothermic decomposition reaction of the organic resin as well as the mass gas flow arising from the decomposition reaction besides the basic heat conduction evaluation.

\begin{tabular}{cccc}
\hline Material & $\begin{array}{c}\text { Density } \\
{\left[\mathrm{kg} / \mathrm{m}^{3}\right]}\end{array}$ & $\begin{array}{c}\text { Specific Heat Capacity } \\
{[\mathrm{J} / \mathrm{kg} / \mathrm{K}]}\end{array}$ & $\begin{array}{c}\text { Thermal Conductivity } \\
{[\mathrm{W} / \mathrm{K} / \mathrm{m}]}\end{array}$ \\
\hline AA2024 & 2700 & 900 & 121 \\
CFRP & 1580 & 1110 & 0.33 \\
PML & 2450 & 1000 & 1.09 (pristine) \\
& & & 0.095 (expanded) \\
\hline
\end{tabular}

Table 1. Some property data of PML thermal barriers, CFRP and AA2024 substrate materials for use in the thermal response model.

It is assumed that sustained heat transfer takes place at the boundary between the PML layer and the substrate material so that no heat losses occur at the interface. The boundary conditions are set to radiant heat transfer of known heat flux at the hot face of the specimen, and given as insulated at the cold face. The developed model should be valid for low heat fluxes, 20-35 $\mathrm{kW} / \mathrm{m}^{2}$, up to heat flux levels where physical damage to the PML surface layers occurs. At heat flux levels above $70 \mathrm{~kW} / \mathrm{m}^{2}$ the PML surface temperatures exceeds the melting point of aluminium which causes irreversible foil damage. The consequent effect on the temperature evolution within the specimen is currently not implemented in the model.

Figure 13 presents the temperature profiles for PML-protected specimens of both AA2024 and CFRP substrates tested during fire-structural exposure at $50 \mathrm{~kW} / \mathrm{m}^{2}$ heat flux. It shows through comparison of the calculated and measured temperature-time curves the good accuracy in the conformity of the curves that can be achieved with the simple modelling approach presented here. 


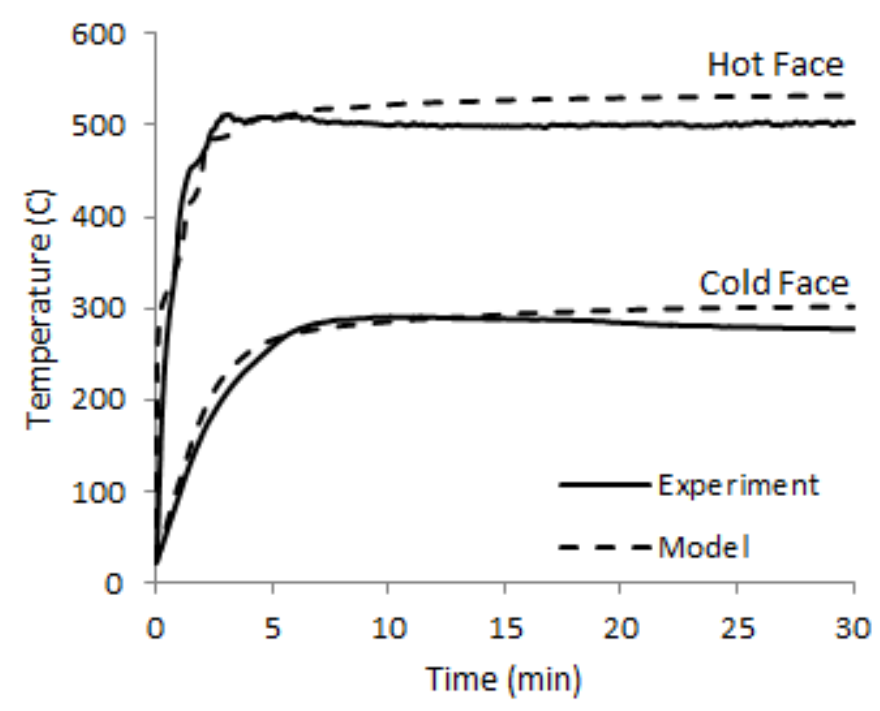

(a)

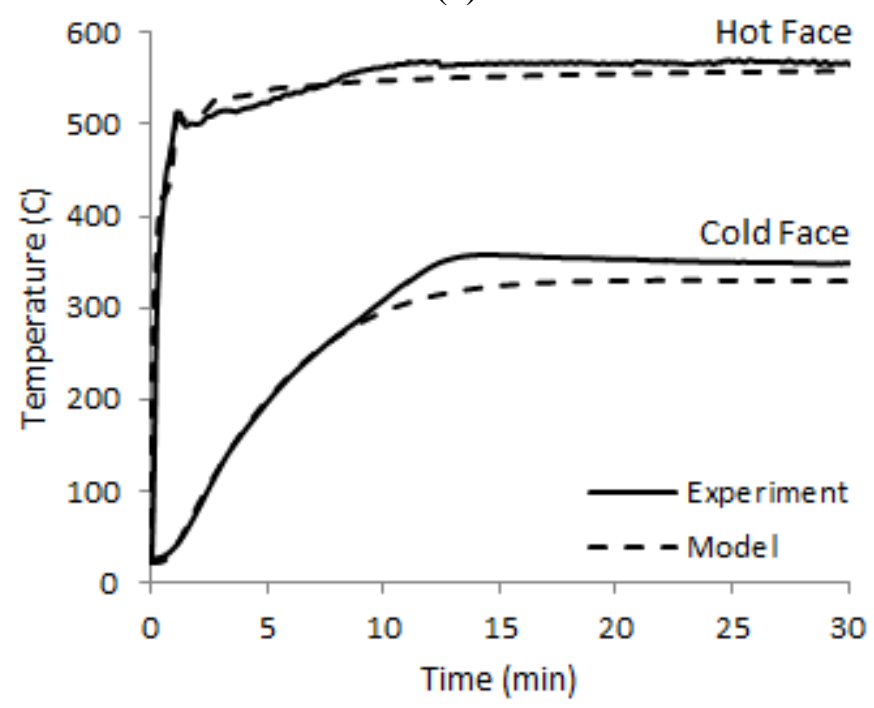

(b)

Figure 13. Comparison of calculated and measured temperature profiles of (a) 10-ply PML/AA2024 specimen and (b) 20-ply PML/CFRP specimen under $50 \mathrm{~kW} / \mathrm{m}^{2}$ heat exposure.

\section{CONCLUSIONS}

A novel surface barrier system that combines mechanical performance with thermal insulation has been developed to protect structural materials from fire. The multi-layered system consisting of alternating metal foil and polymer layers has higher stiffness and strength properties than conventional fire protection systems (e.g. ceramic fibre mats, intumescent films). When exposed to high temperature fire, the polymer layers decompose with the generation of volatiles which are trapped between the metal foils. The metal foils delaminate and move apart under the high pressure exerted by the volatiles to create a thick, insulating barrier protecting the underlying substrate. The metal foils also soften at high temperature, 
which aids their delamination and deformation under the pressure of the volatiles. The insulating effect of the expanded coating lowers the temperature of the substrate. This cooling effect increases the fire structural survivability of substrates such as aluminium alloy and carbon-epoxy composite. Furthermore, the insulation efficiency of the coating is similar to conventional thermal coatings such as ceramic fibre mat and intumescent films, but with the added benefit of having stiffness and strength which contributes to the load-bearing capacity of the structure.

\section{Acknowledgements}

S. Christke thanks the Endeavour Scholarship Foundation, Government of Australia, for support to undertake some of this research at RMIT University. The UK part of the work was funded under the EU FIRE_RESIST $7^{\text {th }}$ Framework programme.

\section{REFERENCES}

1. Qiang X, Bijlaard FSK, Kolstein H. Deterioration of mechanical properties of high strength structural steel S460N under steady-state fire condition. Mats \& Design. 36;2012:438-442.

2. Qiang X, Bijlaard FSK, Kolstein H. Deterioration of mechanical properties of high strength structural steel S460N under transient state fire condition. Mats \& Design. 40;2012:521-527.

3. Maljaars J, Soetens F, Snijder H. Local buckling of aluminium structures exposed to fire. Part 1: Tests. Thin-Walled Structures. 2009;47:1404-17.

4. Maljaars J, Soetens F, Katgerman L. Constitutive model for aluminum alloys exposed to fire conditions. Metallurgical and Materials Transactions A. 2008;39:778-89.

5. Maljaars J, Soetens F, Snijder HH. Local buckling of aluminium structures exposed to fire Part 2: Finite element models. Thin-Walled Structres. 2009;47:1418-28.

6. Maljaars J, Soetens F, Snijder H. Local buckling of fire-exposed aluminum members: New design model. Journal of structural engineering. 2009;136:66-75.

7. Kandare E, Feih S, Kootsookos A, Mathys Z, Lattimer B, Mouritz A. Creep-based life prediction modelling of aluminium in fire. Materials Science and Engineering: A. 2010;527:1185-93.

8. Kandare E, Feih S, Lattimer B, Mouritz A. Larson-Miller failure modeling of aluminum in fire. Metallurgical and materials transactions A. 2010;41:3091-9.

9. Feih S, Kandare E, Lattimer B, Mouritz A. Structural analysis of compression deformation and failure of aluminum in fire. Journal of Structural Engineering. 2010;137:728-38.

10. Fogle EJ, Lattimer BY, Feih S, Kandare E, Mouritz AP, Case SW. Compression load failure of aluminum plates due to fire. Engineering Structures. 2012;34:155-62.

11. Afaghi Khatibi A, Kandare E, Feih S, Lattimer B, Case S, Mouritz A. Finite element modelling of tensile deformation and failure of aluminium plate exposed to fire. Computational Materials Science. 2014;95:242-9.

12. Mouritz AP, Gibson AG. Fire properties of polymer composite materials: Springer; 2007.

13. Mouritz AP, Feih S, Kandare E, Mathys Z, Gibson AG, Des Jardin PE, Case SW, Lattimer BY, Review of fire structural modelling of polymer composites, Comp A, 2009;40:18001814. 
14. Cuce E, Cuce PM, Wood CJ, Riffat SB. Toward aerogel based thermal superinsulation in buildings: A comprehensive review, Renewable and Sustainable Energy Reviews, 2014;34:273-299.

15. Wang M, Pan N. Modeling and prediction of the effective thermal conductivity of random open-cell porous foams, Int J Heat and Mass Transfer, 2008;51:1325-1331.

16. Wei G, Liu Y, Zhang X, Yu F, Du X. Thermal conductivities study on silica aerogel and its composite insulation materials, Int J Heat and Mass Transfer, 2011;54:2355-2366.

17. Tewarson A, Macaione DP. Polymers and composites - an examination of flame spread and generation of heat and fire products. J Fire Sci. 1993;11:421-441.

18. Koksal F, Gencel O, Bristow W, Hagg Lobland HE. Effect of high temperature on mechanical and physical properties of lightweight cement based refractory including vermiculite. Mats Research Inn. 2012;16:7-13.

19. Dupuesne S, Le Bras M, Bourbigot S, Delobel R, Vezin H, Camino G, Eling B, Lindsay C, Roels T. Expandable graphite: A fire retardant additive for polyurethane coatings. Fire \& Mats. 2003;27:103-117.

20. Papakonstantinou CG, Giancaspro JW, Balaguru PN. Fire response and mechanical properties of polysialate syntactic foams. Comp A. 2008;39:75-84.

21. Gupta N, Zelthmann SE, Shunmugasamy VC, Pinisetty D. Applications of polymer matrix syntactic foams. J Mats. 2014;66:245-254.

22. Sorathia U, Gracik T, Ness J, Durkin A, Williams F, Hunstad M, Berry F. Evaluation of intumescent coatings for naval inferior ship applications. Fire \& Mats. 1995;19:423-450.

23. Brown JR, Mathys Z, Riddell SZ, Wake LV. Fire-retardant performance of some surface coatings for naval ship applications. J Fire Sci. 1995;19:109-118.

24. Horacek H, Pieh S. The importance of intumescent systems for fire protection of plastic materials. Poly Int. 2000;49:1106-1114.

25. Yew MC, Sulong NHR. Fire-resistive performance of intumescent flame-retardant coatings for steel. Mats \& Design. 2012;34:719-724.

26. Giancaspro J, Balaguru P, Lyon R. Fire protection of flammable materials utilizing geopolymer. SAMPE J. 2004;40:42-49.

27. Majidi B. Geopolymer technology, from fundaments to advanced applications: a review. Mats Tech. 2009;24:79-87.

28. Temuujin J, Rickard W, Lee M, van Riessen A. Preparation and thermal properties of fire resistant metakaolin-based geopolymer-type coatings. J Non-Cryst Solids. 2011:357:13991404.

29. Wu Q, Zhu W, Zhang C, Liang Z, Wang B. Study of fire retardant behavior of carbon nanotube membranes and carbon nanofiber paper in carbon fiber reinforced epoxy composites. Carbon. 2010;48:1799-1806.

30. Fu X, Zhang C, Liu T, Liang R, Wang B. Carbon nanotube buckypaper to improve fire retardancy of high-temperature/high-performance polymer composites. Nanotech. 2010;21:Number 23.

31. Vogelesang LB, Vlot A. Development of fibre metal laminates for advanced aerospace structures. J Mats Processing Tech, 2000;103(1):1-5.

32. Sinmazcelik T, Avcu E, M.O. Bora MO, Coban O. A review: Fibre metal laminates, background, bonding types and applied test methods. Mats \& Design, 2011;32(7):36713685 .

33. Gibson AG, Browne TNA, Feih S, Mouritz AP. Modeling composite high temperature behaviour and fire response under load, J Comp Mats, 2012;46(16):2005-2022.

34. Feih S, Mathys Z, Gibson AG, Mouritz AP. Modelling the tension and compression strengths of polymer laminates in fire, Comp Sci Tech, 2007;67:551-564. 
35. Gibson AG, Wu H, Chandler HW, Wilcox JAD, Bettess P. Model for the thermal performance of thick composite laminates in hydrocarbon fires. Revue de l'Institute Francais du Petrole, 1995; 50(1):69-74.

36. Henderson JB, Wiebelt JA, Tant MR. Model for the thermal response of polymer composite materials with experimental verification. J Comp Mats, 1985;19(6):579-595. 